DOI: $10.4274 /$ jarem.galenos.2021.18209

J Acad Res Med 2021;11(2):219-26

\title{
Evaluation of the Causes for Repeated Endoscopic Retrograde Cholangiopancreatography in the Early Period
}

\author{
(1) Murat Akaydın1, (1) Okan Demiray2 \\ ${ }^{1}$ Academic Hospital, Clinic of General Surgery, İstanbul, Turkey \\ 2University of Health Sciences Turkey, Taksim Research and Training Hospital, Clinic of General Surgery, İstanbul, Turkey
}

Cite this article as: Akaydın M, Demiray O. Evaluation of the Causes for Repeated Endoscopic Retrograde Cholangiopancreatography in the Early Period. J Acad Res Med 2021;11(2):219-26

\begin{abstract}
Objective: Endoscopic retrograde cholangiopancreatography (ERCP) is the most important invasive endoscopic procedure for the clearance of bile duct stones. Several factors may interfere with a positive outcome in the first attempt. It is important for the endoscopist and the patient to predict under which circumstances repeated intervention may be required. The aim of this study was to determine the conditions in which the need for repeated ERCP increases in patients who have undergone ERCP for bile duct stones.

Methods: Data collected from the procedures performed by a single endoscopist between 2005 and 2020 were analyzed retrospectively. The findings obtained from 100 cases whose bile duct stones were cleared in a single procedure were compared with those of 100 cases who required repeated ERCP in the early period. The demographic findings of the patients, laboratory examinations, difficulty of common bile duct (CBD) stones, clinical manifestation of cholangitis, anatomical and pathological conditions of the patients, factors that complicated the ERCP procedure, and consequently the effect of these factors on post-ERCP complications were investigated in both groups.

Results: According to the results of this study, the diameter of the CBD and the number of stones increased in elderly patients. On the other hand, the presence of stenosis, enclaved stones in the CBD, and accompanying pancreatitis increased the need for repeated ERCP in young patients. In the prediction of single and repeated ERCP using the univariate model, a significant association $(p<0.05)$ was observed between post-ERCP complications and age, white blood cell count, aspartate aminotransferase (AST), alanine aminotransferase, total bilirubin, direct bilirubin, width, angulation, and shape of the CBD, fever and chills, biliary pancreatitis, cholangitis, and difficult stones. In the prediction of single and repeated ERCP using the multivariate model, a significant association $(p<0.05)$ was observed between post-ERCP complications and AST, fever and chills, biliary pancreatitis, and difficult stones.

Conclusion: The need for stenting was higher in both age groups when cholangitis was present. The success rate of ERCP was not affected by a single factor, but by all clinical and pathological factors that increase the difficulty of the procedure.

Keywords: Bile duct angulation, cholangitis, choledocholithiasis, common bile duct stones, difficult common bile duct stones, ERCP, pancreatitis, pre-cut sphincterotomy, repeated ERCP, suppurative cholangitis
\end{abstract}

ORCID IDs of the authors: M.A. 0000-0002-1828-7068; O.D. 0000-0001-6920-7585. 


\section{INTRODUCTION}

Despite it being the gold standard for the treatment of choledochal stones, clearance of the common bile duct (CBD) stones with endoscopic retrograde cholangiopancreatography (ERCP) may not be successful in the first attempt in some patients. Although gallstones are prevalent in $15-20 \%$ of the general population, the prevalence of the choledochal stones observed concomitantly with gallstones is reported to be $3-10 \%$ in the literature (1-7). In addition to clinical evaluation, advanced imaging methods, such as ultrasonography (USG), magnetic resonance cholangiopancreatography (MRCP), and endoscopic ultrasonography (EUS) are diagnostic modalities used to diagnose bile duct stones. With a success rate of $90 \%, \mathrm{MRCP}$ is the most accurate imaging method $(6,8)$. The invasive ERCP procedure is widely replaced by MRCP and EUS as a diagnostic tool and is predominantly used for treatment purposes in current practice (9). The failure rate of selective CBD cannulation in ERCP varies between 5 and 15\% $(5,10,11)$. Advanced endoscopic, surgical, and percutaneous techniques may be indicated in the presence of CBD stones which cannot be removed with a standard ERCP intervention and in cases with altered biliary anatomy $(6,9)$.

The incidence rate of CBD stones is currently increasing with advanced age due to the increasing average age and changes in food habits $(5,11,12)$. In this age group, the prevalence of stones which cannot be cleared with a single attempt has also been increasing. In many patients, stenting is required to prevent prolonged ERCP procedure risks resulting from anatomical difficulties, such as juxtapapillary diverticulum, difficult CBD stones, and increased frequency of cholangitis. The success rate of repeated ERCP interventions were reported to be higher with more satisfactory results being achieved $(6,7,13,14)$. The aim of this study was to determine the conditions in which the need for repeated ERCP increases in patients who have undergone ERCP for bile duct stones.

\section{METHODS}

In this study, the files of patients who had undergone ERCP by the same endoscopist in different health institutions for CBD stones between 2005 and 2020 were retrospectively reviewed. The patients were evaluated according to age, gender, pre-procedural laboratory tests, imaging methods, anatomopathological conditions, bile duct factors, and stone conditions. Preprocedural complaints (pain, icterus, fever, and chills), cholangitis, and a history of biliary pancreatitis were investigated to evaluate whether they had any effect on repeated ERCP.

All laboratory tests related to biliary tract pathologies were performed. The differences between the laboratory tests of the two groups were investigated. Pre-procedural USG and MRCP examinations were performed for the detection of CBD stones. In non-emergency situations, the patients sent to our reference hospital were subjected to MRCP for a detailed detection of pancreatic and biliary tract pathologies. In patients with acute biliary pancreatitis, early ERCP was planned if findings of acute cholangitis were present, while in the absence of these findings, the procedure was delayed until the patient's general condition improved.

The condition of the papilla, presence of juxtapapillary diverticulum, appearance of the papilla, presence of very rarely observed findings of choledochoduodenal fistula, and cannulation success were defined. Needle-knife sphincterotomy was the method of choice in patients who were unsuitable for early selective cannulation, especially in the presence of papillary protrusion. However, if cannulation was not present, the procedure was suspended to be repeated. Contrast material was administered after confirming the selective cannulation of the CBD with a guidewire or through the aspiration of bile. In the endoscopic examination, the diameter of the CBD was determined using the image of the extrahepatic biliary tract axis, and the CBD angulation was measured. Extraction of stone/ sludge/pus during the procedure was also investigated. The diameter and localization of the stones were recorded. Single stones $>15 \mathrm{~mm}$, multiple stones $<15 \mathrm{~mm}$, enclaved CBD stones, distal stenosis of the $\mathrm{CBD}$, and stones requiring mechanical lithotripsy were considered as difficult CBD stones. Patients with choledochoduodenal fistula, T-tube in situ, or intraprocedural basket impaction were also included in this group. Patients with intrahepatic stones and modified anatomy were not included in this study. All these anatomopathological factors were evaluated in both groups. These factors may be summarized as the presence of juxtapapillary diverticulum, unsuccessful cannulation, and presence of pre-cut sphincterotomy and difficult CBD stones.

Endoscopic biliary stenting was performed in cases where adequate clearing of the stones could not be achieved despite prolongation of the procedure, especially in those with concomitant cholangitis. Our first choice was a $10-\mathrm{F}$ Amsterdam-type plastic stent. However, in patients with severe cholangitis, a dilated CBD, and multiple stones, we preferred a pigtail stent.

Procedural complications included inadequate ERCP, difficult CBD stones, residual stones, and cholangitis. Two groups were formed with 100 patients each, who were selected consecutively; the single ERCP group, in which the initial attempt of stone clearance was successful and repeated ERCP was not required in the early period, and the repeated ERCP group, in which a second procedure was required within a month of the initial procedure due to inadequate stone clearance, stenting, failed cannulation, or basket impaction.

\section{Statistical Analysis}

Descriptive statistics of the data used the mean, standard deviation, median, minimum, maximum, frequency, and ratio values. The distribution of variables was determined with the Kolmogorov-Smirnov test. The independent-samples t-test and Mann-Whitney $U$ test were used for the analysis of continuous 
tamponade and injection control. Basket impaction developed in three of our patients, of whom two were treated endoscopically and one was treated by open surgery.

The complication rate was significantly higher in the repeated ERCP group than in the single ERCP group $(p<0.05)$ (Table 3 ). Post-procedural pancreatitis was detected in a patient of the single ERCP group and in five cases of the repeated ERCP group. In addition, the repeated ERCP group comprised 16 patients who developed cholangitis requiring temporary or early ERCP intervention. However, mortality was not observed in these patients.

Imaging performed under endoscopy generally revealed three different types of CBD courses. The straight course was mainly seen in the young patients with a smaller number of stones, V-type angulation was observed in 71 patients, and the S-type CBD course was predominantly observed in elderly patients with larger and more stones (Table 4).

\section{differ significantly in terms of the duration of complaints $(p>0.05)$} The length of complaints did not differ with regard to the number of ERCPs (Table 2).

Compared to the single ERCP group, aspartate aminotransferase (AST) and alanine aminotransferase (ALT) levels were significantly higher in repeat ERCP group $(p<0.05)$. The gamma glutamyl transferase, alkaline phosphatase, amylase, and indirect bilirubin levels showed a significant difference between the two groups $(p<0.05)$. However, the repeated and single ERCP groups did not differ significantly in terms of the number of gallstones ( $p>0.05)$. Although juxtapapillary diverticulum was commonly observed in the repeated ERCP group, the difference was not significant between the groups (Table 2).

Compared to the single ERCP group, the presence of preprocedural biliary pancreatitis and the prevalence of difficult CBD stones were significantly higher in the group with repeated ERCP ( $p<0.05$ for both). Additional factors other than the size and number of stones, including age, presence of fever and chills, biliary pancreatitis, cholangitis, white blood cell (WBC), AST, ALT, and total and direct bilirubin levels were also increased with the difficulty of the procedure $(p<0.05)$ (Table 2$)$.

Similarly, when we compared the two groups according to the anatomical structure of the biliary system and diseaserelated variables, the width of the CBD and the number of $V$-type CBDs were significantly higher in the repeated ERCP group than in the single ERCP group $(p<0.05)$. Moreover, CBD angulation was significantly smaller in the repeated ERCP group compared to that in the single ERCP group $(p<0.05)$ (Table 3).

The single and repeated ERCP groups did not show a significant difference in terms of the intraprocedural complications ( $p>0.05)$. Intraprocedural and post-ERCP complications are presented in Table 3. During the procedure, only 14 of the 200 patients had minimal hemorrhage that did not require blood transfusion. The cases that developed hemorrhage were managed using balloon

\section{Table 1. Demographic status, complaints, blood test results, and the number of ERCPs of the sample}

\begin{tabular}{|c|c|c|}
\hline & & Mean \pm SD $/ n-\%$ \\
\hline Age & & $61.1 \pm 16.5$ \\
\hline \multirow{2}{*}{ Gender } & Female & $128 / 64.0 \%$ \\
\hline & Male & $72 / 36.0 \%$ \\
\hline \multicolumn{3}{|l|}{ Complaint } \\
\hline \multicolumn{2}{|l|}{ Pain } & $194 / 97.0 \%$ \\
\hline \multicolumn{2}{|l|}{ Jaundice } & $142 / 71.0 \%$ \\
\hline \multicolumn{2}{|l|}{ Fever-chills } & $62 / 31.0 \%$ \\
\hline \multicolumn{2}{|l|}{ Biliary pancreatitis } & $55 / 27.5 \%$ \\
\hline \multicolumn{2}{|l|}{ Cholangitis } & $118 / 59.0 \%$ \\
\hline \multicolumn{2}{|l|}{ Gallstone } & $136 / 68.0 \%$ \\
\hline \multicolumn{2}{|l|}{ Duration of complaint } & $16.8 \pm 28.4$ \\
\hline \multicolumn{2}{|l|}{ WBC $\left(\mu \mathrm{L} \times 10^{3}\right)$} & $10.6 \pm 4.1$ \\
\hline \multicolumn{2}{|l|}{ AST (U/L) } & $211.1 \pm 219.3$ \\
\hline \multicolumn{2}{|l|}{$\mathrm{ALT}(\mathrm{U} / \mathrm{L})$} & $271.9 \pm 226.4$ \\
\hline \multicolumn{2}{|l|}{ GGT (U/L) } & $521.6 \pm 381.1$ \\
\hline \multicolumn{2}{|l|}{$\operatorname{ALP}(\mathrm{U} / \mathrm{L})$} & $453.8 \pm 323.2$ \\
\hline \multicolumn{2}{|l|}{ Amylase (U/L) } & $343.6 \pm 685.3$ \\
\hline \multicolumn{2}{|l|}{ Total bilirubin mg/dL } & $5.5 \pm 4.1$ \\
\hline \multicolumn{2}{|l|}{ Direct bilirubin mg/dL } & $4.1 \pm 3.3$ \\
\hline \multicolumn{2}{|l|}{ Indirect bilirubin mg/dL } & $1.4 \pm 1.5$ \\
\hline \multirow{5}{*}{ Number of ERCPs } & 1 & $100 / 50.0 \%$ \\
\hline & 2 & $73 / 36.5 \%$ \\
\hline & 3 & $24 / 12.0 \%$ \\
\hline & 4 & $2 / 1.0 \%$ \\
\hline & 5 & $1 / 0.5 \%$ \\
\hline \multicolumn{3}{|c|}{$\begin{array}{l}\text { SD: standard deviation, WBC: white blood cell, AST: aspartate } \\
\text { aminotransferase, ALT: alanine aminotransferase, GGT: gamma glutamyl } \\
\text { transferase, ALP: alkaline phosphatase, ERCP: endoscopic retrograde } \\
\text { cholangiopancreatography }\end{array}$} \\
\hline
\end{tabular}


In the prediction of single and repeated ERCP using the univariate model, a significant association was observed between postERCP complications and age, WBC, AST, ALT, total bilirubin, direct bilirubin, width of $C B D$, angulation of $C B D$, fever and chills, biliary pancreatitis, cholangitis, difficult stones, and shape of the CBD $(p<0.05)$. In the prediction of single and repeated ERCP using the multivariate model, there was a significant association between post-ERCP complications and AST, fever and chills, biliary pancreatitis, and the presence of difficult stones $(p<0.05)$ (Table 5).

\section{DISCUSSION}

In this study, the age of the patients was significantly higher in the repeated ERCP group than in the single ERCP group. There are two possible reasons for this: First, the prevalence of problematic stones increases as the median age increases. In a study investigating the effectiveness and reliability of ERCP in patients $\geq 85$ years, larger stones were detected in the elderly group (15). In some studies, the total clearance of stones was significantly limited in the elderly population $(8,15,16)$. Second, in elderly patients, procedures are often delayed until second

Table 2. Comparison of demographic status, complaints, and blood test results of the single and repeated ERCP groups

\begin{tabular}{|c|c|c|c|c|}
\hline & $\begin{array}{l}\text { Single } \\
\text { ERCP }\end{array}$ & $\begin{array}{l}\text { Repeated } \\
\text { ERCP }\end{array}$ & \multirow[b]{2}{*}{$p$} \\
\hline & & $\begin{array}{l}\text { Mean } \pm \text { SD/ } \\
n-\%\end{array}$ & $\begin{array}{l}\text { Mean } \pm \text { SD/ } \\
n-\%\end{array}$ & \\
\hline \multicolumn{2}{|l|}{ Age } & $57.8 \pm 17.5$ & $64.4 \pm 14.9$ & $0.007^{\mathrm{m}}$ \\
\hline \multirow{2}{*}{ Gende } & Female & $70 / 70.0 \%$ & $58 / 58.0 \%$ & \multirow{2}{*}{$0.077^{x^{2}}$} \\
\hline & Male & $30 / 30.0 \%$ & $42 / 42.0 \%$ & \\
\hline \multicolumn{5}{|c|}{ Complaint } \\
\hline \multicolumn{2}{|l|}{ Pain } & $99 / 99.0 \%$ & $95 / 95.0 \%$ & $0.097^{x^{2}}$ \\
\hline \multicolumn{2}{|c|}{ Jaundice } & $67 / 67.0 \%$ & $75 / 75.0 \%$ & $0.213^{x^{2}}$ \\
\hline \multicolumn{2}{|c|}{ Fever-chills } & $21 / 21.0 \%$ & $41 / 41.0 \%$ & $0.002^{x^{2}}$ \\
\hline \multicolumn{2}{|c|}{ Biliary pancreatitis } & $35 / 35.0 \%$ & $20 / 20.0 \%$ & $0.018^{x^{2}}$ \\
\hline \multicolumn{2}{|c|}{ Cholangitis } & $51 / 51.0 \%$ & $67 / 67.0 \%$ & $0.021^{x^{2}}$ \\
\hline \multicolumn{2}{|c|}{ Gallstone } & $70 / 70.0 \%$ & $66 / 66.0 \%$ & $0.544^{x^{2}}$ \\
\hline \multicolumn{2}{|c|}{ Complaint duration } & $13.4 \pm 10.8$ & $20.2 \pm 38.5$ & $0.076^{m}$ \\
\hline \multicolumn{2}{|c|}{ WBC $\left(\mu \mathrm{L} \times 10^{3}\right)$} & $9.8 \pm 3.7$ & $11.4 \pm 4.3$ & $0.004^{m}$ \\
\hline \multicolumn{2}{|c|}{ AST (U/L) } & $258.7 \pm 268.6$ & $163.5 \pm 141.4$ & $0.002^{\mathrm{m}}$ \\
\hline \multicolumn{2}{|c|}{$\operatorname{ALT}(U / L)$} & $321.2 \pm 249.0$ & $222.6 \pm 190.1$ & $0.001^{m}$ \\
\hline \multicolumn{2}{|c|}{ GGT (U/L) } & $517.2 \pm 393.7$ & $526.0 \pm 370.1$ & $0.782^{m}$ \\
\hline \multicolumn{2}{|c|}{ ALP (U/L) } & $441.5 \pm 314.0$ & $466.2 \pm 333.3$ & $0.327^{m}$ \\
\hline \multicolumn{2}{|c|}{ Amylase (U/L) } & $467.2 \pm 870.5$ & $219.9 \pm 394.1$ & $0.164^{\mathrm{m}}$ \\
\hline \multicolumn{2}{|c|}{ Total bilirubin mg/dL } & $4.7 \pm 3.6$ & $6.2 \pm 4.6$ & $0.006^{m}$ \\
\hline \multicolumn{2}{|c|}{ Direct bilirubin mg/dL } & $3.6 \pm 3.3$ & $4.6 \pm 3.3$ & $0.013^{m}$ \\
\hline \multicolumn{2}{|c|}{ Indirect bilirubin mg/dL } & $1.3 \pm 1.0$ & $1.6 \pm 1.9$ & $0.269^{m}$ \\
\hline \multicolumn{5}{|c|}{$\begin{array}{l}\text { "mann-Whitney U test, }{ }^{2} \text { chi-square test (Fisher's Exact test), SD: standaro } \\
\text { deviation, WBC: white blood cell count, AST: aspartate aminotransferase, ALT } \\
\text { alanine aminotransferase, GGT: gamma glutamyl transferase, ALP: alkaline } \\
\text { phosphatase, ERCP: endoscopic retrograde cholangiopancreatography }\end{array}$} \\
\hline
\end{tabular}

intervention to avoid the complications of prolonged ERCP and anesthesia (17).

Although a higher number of repeated ERCP procedures are performed in the elderly, non-significant differences in gender, patient complaints, and duration of the complaints were expected. Especially, fever and chills, elevated WBC, and increased total and direct bilirubin values were found to be significantly higher when evaluated together. These findings represent cholangitis cases,

Table 3. Comparison of CBD anatomical features, stones, and procedure-related parameters of the single and repeated ERCP groups

\begin{tabular}{|c|c|c|c|c|}
\hline & \multirow{2}{*}{$\begin{array}{l}\text { Single } \\
\text { ERCP } \\
\text { Mean } \pm \\
\text { SD/n-\% }\end{array}$} & \multirow{2}{*}{$\begin{array}{l}\text { Repeat } \\
\text { ERCP } \\
\text { Mean } \pm \\
\text { SD/n-\% }\end{array}$} & \multirow[b]{2}{*}{$p$} \\
\hline & & & & \\
\hline \multicolumn{2}{|l|}{ CBD width } & $12.3 \pm 4.3$ & $15.2 \pm 5.0$ & $0.000^{m}$ \\
\hline \multirow{3}{*}{ CBD width } & $<10 \mathrm{~mm}$ & $44 / 44.0 \%$ & $22 / 22.0 \%$ & \multirow{3}{*}{$0.001^{x^{2}}$} \\
\hline & $10-20 \mathrm{~mm}$ & $46 / 46.0 \%$ & $53 / 53.0 \%$ & \\
\hline & $>20 \mathrm{~mm}$ & $10 / 10.0 \%$ & $25 / 25.0 \%$ & \\
\hline $\begin{array}{l}\text { CBD } \\
\text { angulation }\end{array}$ & & $288.9 \pm 38.7$ & $273.7 \pm 36.9$ & $0.001^{m}$ \\
\hline \multirow{3}{*}{$\begin{array}{l}\text { CBD } \\
\text { angulation }\end{array}$} & $<250^{\circ}$ & $20 / 20.0 \%$ & $32 / 32.0 \%$ & \multirow{3}{*}{$0.008^{x^{2}}$} \\
\hline & $250^{\circ}-300^{\circ}$ & $32 / 32.0 \%$ & $41 / 41.0 \%$ & \\
\hline & $\Rightarrow 300^{\circ}$ & $48 / 48.0 \%$ & $27 / 27.0 \%$ & \\
\hline \multirow{3}{*}{$\begin{array}{l}\text { Number of } \\
\text { gallstones }\end{array}$} & Several & $58 / 58.0 \%$ & $50 / 50.0 \%$ & \multirow{3}{*}{$0.467^{x^{2}}$} \\
\hline & Single & $3 / 3.0 \%$ & $5 / 5.0 \%$ & \\
\hline & None & $39 / 39.0 \%$ & $45 / 45.0 \%$ & \\
\hline \multirow{4}{*}{$\begin{array}{l}\text { Stone } \\
\text { difficulty }\end{array}$} & Sludge & $28 / 28.0 \%$ & $3 / 3.0 \%$ & \multirow{4}{*}{$0.000^{x^{2}}$} \\
\hline & $<10 \mathrm{~mm}$ & $50 / 50.0 \%$ & $24 / 24.0 \%$ & \\
\hline & $\begin{array}{l}10-14 \mathrm{~mm} \\
\text { single stone }\end{array}$ & $9 / 9.0 \%$ & $21 / 21.0 \%$ & \\
\hline & $\begin{array}{l}8-12 \mathrm{~mm} \\
\text { multiple } \\
\text { stones }\end{array}$ & $13 / 13.0 \%$ & $52 / 52.0 \%$ & \\
\hline \multirow{3}{*}{ CBD shape } & Straight & $7 / 7.0 \%$ & $6 / 6.0 \%$ & \multirow{3}{*}{$0.042^{x^{2}}$} \\
\hline & V-type & $27 / 27.0 \%$ & $44 / 44.0 \%$ & \\
\hline & S-type & $66 / 66.0 \%$ & $50 / 50.0 \%$ & \\
\hline \multirow{4}{*}{$\begin{array}{l}\text { ERCP } \\
\text { complication }\end{array}$} & $(-)$ & $95 / 95.0 \%$ & $88 / 88.0 \%$ & \multirow{4}{*}{$0.128^{x^{2}}$} \\
\hline & $(+)$ & $5 / 5.0 \%$ & $12 / 12.0 \%$ & \\
\hline & Hemorrhage & $5 / 5.0 \%$ & $9 / 9.0 \%$ & \\
\hline & $\begin{array}{l}\text { Basket } \\
\text { impaction }\end{array}$ & $0 / 0.0 \%$ & $3 / 3.0 \%$ & \\
\hline \multirow{4}{*}{$\begin{array}{l}\text { Post-ERCP } \\
\text { complication }\end{array}$} & $(-)$ & $99 / 99.0 \%$ & $79 / 79.0 \%$ & \multirow{4}{*}{$0.000^{x^{2}}$} \\
\hline & $(+)$ & $1 / 1.0 \%$ & $21 / 21.0 \%$ & \\
\hline & Pancreatitis & $1 / 1.0 \%$ & $5 / 5.0 \%$ & \\
\hline & Cholangitis & 0/0.0\% & $16 / 16.0 \%$ & \\
\hline \multicolumn{5}{|c|}{$\begin{array}{l}\text { mMann-Whitney } U \text { test, }{ }^{2} \text { chi-square test (Fisher's Exact test) SD: standard } \\
\text { deviation, CBD: common bile duct, WBC: white blood cell count, AST: } \\
\text { aspartate aminotransferase, ALT: alanine aminotransferase, GGT: gamma } \\
\text { glutamyl transferase, ALP: alkaline phosphatase, ERCP: endoscopic } \\
\text { retrograde cholangiopancreatography }\end{array}$} \\
\hline
\end{tabular}


Juxtapapillary diverticulum was more commonly observed in the repeated ERCP group. There are many studies demonstrating that recurrent $\mathrm{CBD}$ stones develop more frequently in the presence of diverticula. Moreover, cholangitis, pancreatitis, and deformation in the choledochal axis are highly prevalent when a duodenal diverticulum is present $(2-4,13)$.

It is generally accepted that ERCP is more challenging in cases with acute pancreatitis. The presence of enclaved CBD stones and a duodenal diverticulum is highly prevalent in cases of acute biliary pancreatitis (7). Increased pressure at the distal end of the CBD due to the developing edema may cause biliary tract obstruction and cholangitis. In case of acute pancreatitis, if there is an obstructing stone that causes acute cholangitis, early ERCP should be planned. Otherwise, unnecessary interventions may increase the severity of pancreatitis. The pathology of such cases should be demonstrated using MRCP or EUS (6,22-24). In late-stage biliary pancreatitis cases, the presence of stones should be investigated with MRCP. Difficulty of CBD cannulation during ERCP increases in patients with acute pancreatitis, and if accompanied by an enclaved stone, stone clearance becomes complicated. The frequency of precut sphincterotomy is high in these patients, which further increases the risk of post-ERCP complications.

Pre-cut access to the CBD is more efficient in cases with enclaved CBD stones. Although these stones are typically difficult to treat, it is possible to easily remove the stone and perform selective cannulation through the efficient sphincterotomy. Precut sphincterotomy can be successfully performed in patients undergoing ERCP, especially in experienced hands. It is required in $10 \%$ of all cases $(13,25,26)$. If cannulation cannot be performed in patients with a pre-cut sphincterotomy, extending the duration of ERCP increases the rate of post-procedural complications (25). Pavlides et al. (26) reported a $78 \%$ success rate in cannulation when they repeated ERCP within an average of four days in 89 cases for whom successful selective cannulation could not be achieved despite the pre-cut procedure.

In the current study, patients with difficult CBD stones had a significantly higher requirement for repeated ERCP, as expected. In addition, the presence of choledochoduodenal fistula, a wide $C B D$, and use of mechanical lithotripsy during the procedure increased the number of repeated ERCPs (27). It should be kept in mind that most elderly patients have a wide CBD and a high number of stones, often accompanied by cholangitis (2$4,15,18,19,28)$. The presence of large and difficult stones in ERCP complicates stone removal. In such cases, repeated ERCP may be undertaken by performing sphincterotomy and stenting (5). It is extremely important to perform adequate sphincterotomy and ensure adequate stone clearance to reduce the number of repeated ERCPs and minimize residual and recurrent stones in the late period $(5,28)$.

An increase in the diameter of CBD is detected in proportion to the increasing difficulty and size of CBD stones. The increase in the width of $C B D$ is greater in elderly patients when the diameter

SD: standard deviation, ERCP: endoscopic retrograde cholangiopancreatography, CBD: common bile duct 


\begin{tabular}{|c|c|c|c|c|c|c|}
\hline & \multicolumn{3}{|c|}{ Univariate model } & \multicolumn{3}{|c|}{ Multivariate model } \\
\hline Age & 1.03 & $1.01-1.04$ & 0.005 & - & - & - \\
\hline ALT & 1.00 & $1.00-1.00$ & 0.003 & - & - & - \\
\hline Total bilirubin & 1.10 & $1.02-1.19$ & 0.014 & - & - & - \\
\hline Direct bilirubin & 1.10 & $1.00-1.20$ & 0.048 & - & - & - \\
\hline CBD width & 1.15 & $1.07-1.23$ & 0.000 & - & - & - \\
\hline Cholangitis & 1.95 & $1.10-3.46$ & 0.022 & - & - & - \\
\hline Stone difficulty & 3.20 & $2.29-4.48$ & 0.000 & 3.45 & $2.33-5.11$ & 0.000 \\
\hline CBD shape & 1.73 & $1.06-2.83$ & 0.030 & - & - & - \\
\hline Post-ERCP complication & 36.3 & $3.5-200$ & 0.002 & \multirow{3}{*}{6.02} & \multirow{3}{*}{$1.32-27.03$} & \multirow{3}{*}{0.020} \\
\hline CBD width & 2.25 & $1.46-3.47$ & 0.000 & & & \\
\hline CBD angulation & 0.58 & $0.40-0.84$ & 0.003 & & & \\
\hline
\end{tabular}

of the stone is large, the stone is enclaved, or the number of stones is high, all of which contribute to the possibility of repeated ERCP. The width of CBD is also a significant factor in the recurrence of $\mathrm{CBD}$ stones in the long-term. In many studies, post-ERCP follow-up results have demonstrated that CBD width was a significant factor in the long-term recurrence of $C B D$ stones $(6,7,28)$.

In studies concerning the shape and angulation of the CBD, significant results have been obtained, especially regarding recurrent $\mathrm{CBD}$ stones. It was reported that late-stage recurrent stones are more frequently observed, mainly in the S-type CBD structure (28-30). In our study, the need for repeated ERCP attempts was increased by the location, size, and number of stones, rather than the shape of the CBD or the presence of cholangitis.

In the literature, papillary hemorrhage (1.4\%) and retroperitoneal duodenal perforation (0.69\%) were reported as the most frequent complications observed during invasive $\operatorname{ERCP}(6,31,32)$. Among our cases, complications encountered during the procedure were like those reported in the literature. The frequency of mechanical lithotripsy and related complications increase with difficult CBD stones. The most important and challenging complication was basket impaction. In two of our patients, this complication was resolved by the repeated endoscopic intervention, while the remaining patient required open surgery. In case a large stone is detected during the pre-procedural examination, a lithotripter basket should be used while seeking other appropriate solutions to prevent complications $(6,7,13,14)$.

In our study, compared to the single ERCP group, the complication rate in the repeated ERCP group was significantly higher. The most common post-ERCP complication is pancreatitis, with a prevalence of $1.6-15.7 \%(3,11,33,34)$. Etiological factors of this complication include the use of electrocauterization in sphincterotomy, edema in the sphincter of Oddi and the pancreatic sphincter, pre-cut sphincterotomy, increased hydrostatic pressure in the pancreatic duct due to excessive contrast injection, and contamination of the pancreatic ductal system with duodenal content $(26,32)$. All these etiological factors increase with repeated ERCP and naturally result in a significantly higher rate of post-ERCP complications. Biliary septic complications, including cholangitis and cholecystitis are also observed in the post-ERCP period (1,5,32,35-37). The clinical follow-up of these patients is very important, since cholangitis may develop frequently in patients with difficult CBD stones due to inadequate sphincterotomy, overlooked stones, and non-functioning stenting.

\section{Study Limitations}

The study had some limitations. The present study was conducted with ERCP records of a single endoscopist which may cause bias due to personalization of the data. Additionally, there might have been some patients who had undergone repeated ERCP in a different center that we missed during the study period. On the 
other hand, the most important strength of this study that to the best of our knowledge, this is the first study in the literature to include such a large number of patients with a noticeable amount of data and follow-up period.

ERCP is the gold standard in gallstone treatment; therefore, it should be considered as the first-line treatment. However, due to its invasive nature, its risk of complications is high, even in experienced hands. Along with experience, pre-procedural patient selection is a very important factor for reducing complications $(34,36)$.

\section{CONCLUSION}

ERCP is the most important, invasive, endoscopic procedure for the clearance of bile duct stones. It is known that several factors may interfere with a positive outcome in the first attempt. It is important for the endoscopist and the patient to be able to predict under which circumstances a repeat intervention may be required. The diameter of the $\mathrm{CBD}$ and the number of stones was increased in elderly patients. On the other hand, the presence of stenosis, enclaved stones in the CBD, and accompanying pancreatitis increased the need for repeated ERCP in young patients. The need for stenting was higher in both age groups when cholangitis was present. The success rate of ERCP was not affected by a single factor, but by all clinical and pathological factors that increase the difficulty of the procedure.

Ethics Committee Approval: Ethical approval was not sought for the present study because this study did not involve a prospective evaluation, did not involve laboratory animals, and only involved the records of ERCP procedures of different health centers at which Dr. Murat Akaydın had been working.

Informed Consent: Retrospective study.

Peer-review: Internally peer-reviewed.

Author Contributions: Surgical and Medical Practices - M.A.; Concept M.A.; Design - O.D.; Data Collection and/or Processing - M.A.; Analysis and/or Interpretation - O.D.; Literature Search - M.A., O.D.; Writing - O.D.

Conflict of Interest: The authors have no conflict of interest to declare.

Financial Disclosure: The authors declared that this study has received no financial support.

\section{REFERENCES}

1. Ramirez FC, Dennert B, Sanowski RA. Success of repeat ERCP by the same endoscopist. Gastrointest Endosc 1999; 49: 58-61.

2. Lu J, Cheng Y, Xiong XZ, Lin YX, Wu SJ, Cheng NS. Two- stage vs single -stage management for concominant gallstones and common bile duct stones. World J Gastroenterol 2012; 8: 3156-66.

3. Collins C, Maguire D, Ireland A, Fitzgerald E, O'Sullivan GC. A prospective study of common bile duct calculi in patients undergoing laparoscopic cholecystectomy: natural history of choledocholithiasis revisited. Ann Surg 2004; 239: 28-33.

4. Bansal VK, Misra MC, Garg P, Prabhu M. A prospective randomized trial comparing two-stage versus single-stage management of patients with gallstone disease and common bile duct stones. Surg Endosc 2010; 24: 1986-9.

5. Wu Y, Xu CJ, Xu SF. Advances in risk factors for recurrence of common bile duct stones. Int J Med Sci 2021; 18: 1067-74.

6. Manes G, Paspatis G, Aabakken L, Anderloni A, Arvanitakis M, Ah-Soune $P$, et al. Endoscopic management of common bile duct stones: European Society of Gastrointestinal Endoscopy (ESGE) guideline. Endoscopy 2019; 51: 472-91.
7. Lujian P, Xianneng $C$, Lei Z. Risk factors of stone recurrence after endoscopic retrograde cholangiopancreatography for common bile duct stones. Medicine (Baltimore) 2020; 99: e20412.

8. Aranovich D, Zilbermints $V$, Goldberg N, Kaminsky O. Detection of common bile duct stones in mild acute biliary pancreatitis using magnetic resonance cholangiopancreatography. Surg Res Pract 2018; 2018: 5216089. doi: 10.1155/2018/5216089.

9. Molvar C, Glaenzer B. Choledocholithiasis: evaluation, treatment, and outcomes. Semin Intervent Radiol 2016; 33: 268-76.

10. Ramirez FC, Dennert B, Sanowski RA. Success of repeat ERCP by the same endoscopist Gastrointest Endosc 1999; 46: 58-61.

11. Vaira D, Ainsley C, Williams S, Cairns S, Salmon P, Russell C, et al. Endoscopic sphincterotomy in 1000 consecutive patients. Lancet 1989; 2: $431-4$.

12. Deng F, Zhou M, Liu PP, Hong JB, Li GH, Zhou XJ, et al. Causes associated with recurrent choledocholithiasis following therapeutic endoscopic retrograde cholangiopancreatography: A large sample sized retrospective study. World J Clin Cases 2019; 7: 1028-37.

13. Stefanidis G, Christodoulou C, Manolakopoulos S, Chuttani R. Endoscopic extraction of large common bile duct stones: A review article. World J Gastrointest Endosc 2012; 4: 167-79.

14. Trikudanathan G, Navaneethan U, Parsi MA. Endoscopic management of difficult common bile duct Stones. World J Gastroenterol 2013; 19: 16573.

15. Lida T, Kaneto H, Wagatsuma K, Sasaki H, Naganawa Y, Nakagaki S, et al. Efficacy and safety of endoscopic procedures for common bile duct stones in patients aged 85 years or older: A retrospective study. PLoS One 2018; 13: e0190665. doi: 10.1371/journal.pone.0190665.

16. Obana T, Fujita N, Noda Y, Kobayashi G, Ito K, Horaguchi J, et al. Efficacy and safety of therapeutic ERCP for the elderly with choledocholithiasis: Comparison with younger patients. Internal Med 2010; 49: 1935-41.

17. Tohda G, Ohtani M, Dochin M. Efficacy and safety of emergency endoscopic retrograde cholangiopancreatography for acute cholangitis in the elderly. World J Gastroenterol 2016; 22: 8382-8.

18. Kimura $Y$, Takada $T$, Kawarada $Y$, Nimura $Y$, Hirata $K$, Sekimoto $M$, et al. Definitions, pathophysiology, and epidemiology of acute cholangitis and cholecystitis: Tokyo Guidelines J Hepatobiliary Pancreat Surg 2007; 14: 15-26.

19. Lai EC, Tam PC, Paterson IA, Ng MM, Fan ST, Choi TK, et al. Emergency surgery for severe acute cholangitis. The high-risk patients. Ann Surg 1990; 211: 55-9.

20. Mulki R, Shah R, Qayed E. Early vs late endoscopic retrograde cholangiopancreatography in patients with acute cholangitis: a nationwide analysis. World J Gastrointest Endosc 2019; 11: 41-53.

21. Dedemadi G, Nikolopoulos M, Kalaitzopoulos I, Sgourakis G. Management of patients after recovering from acute severe biliary pancreatitis. World J Gastroenterol 2016; 22: 7708-17.

22. Petrescu I, Bratu AM, Petrescu S, Popa BV, Cristian D, Burcos T. CT vs. MRCP in choledocholithiasis jaundice. J Med Life 2015; 8: 226-31.

23. Mustafa A, Begaj I, Dcakin M, Durkin D, Corless DJ, Wilson R, et al. Long term effectiveness of cholecystectomy and endoscopic sphincteretomy in the management of gallstone pancreatitis. Surg Endosc 2014; 28: 12733.

24. Hazem ZM. Acute biliary pancreatitis: diagnosis and treatment. Saudi J Gastroenterol 2009; 15: 147-55.

25. Saritas U, Ustundag Y, Harmandar F. Precut sphincterotomy: a reliable salvage for difficult biliary cannulation. World J Gastroenterol 2013; 19: 1-7.

26. Pavlides $M$, Barnabas A, Fernandopulle N, Bailey AA, Collier $J$, Phillips-Hughes J, et al. Repeat endoscopic retrograde cholangiopancreaticogarphy after failed initial precut sphincterotomy for biliary cannulation. World J Gastroenterol 2014; 20: 13153-8.

27. Akaydin M, Demiray O, Ferlengez E, Erozgen F, Ersoy YE, Er M. Importance of spontaneous choledochoduodenal fistulas detected during ERCP procedure. Indian J Surg 2018; 80: 216-20.

28. Konstantakis C, Triantos C, Theopistos V, Theocharis G, Maroulis I, Diamantopoulou G, et al. Recurrence of choledocholithiasis following endoscopic bile duct clearance: long term results and factors associated with recurrent bile duct stones. World J Gastrointest Endosc 2017; 9: 26-33. 
29. Seo DB, Bang BW, Jeong S, Lee DH, Jeon YS, Lee JW, et al. Does the bile duct angulation affect recurrence of choledocholithiasis? World J Gastroenterol 2011; 17: 4118-23.

30. Ryu S, Jo IH, Kim S, Kim YJ, Chung WC. Clinical impact of common bile duct angulation on the recurrence of common bile duct stone: a metaanalysis and review. Korean J Gastroenterol 2020; 76: 199-205.

31. Baek YH, Kim HJ, Park JH, Park DI, Cho YK, Sohn Cl, et al. [Risk factors for recurrent bile duct stones after endoscopic clearance of common bile duct stones]. Korean J Gastroenterol 2009; 54: 36-4.

32. lorgulescu A, Sandu I, Turcu F, lordache N. Post-ERCP acute pancreatitis and its risk factors. J Med Life 2013; 6: 109-13

33. Andriulli A, Loperfido S, Napolitano G, Niro G, Valvano MR, Spirito F, et al. Incidence rates of postERCP complications: a systematic survey of prospective studies. Am J Gastroenterol 2007; 102: 1781.
34. Anderson MA, Fisher L, Sharaf RN, Shergill AK, Dominitz JA, Appalaneni $V$, et al. Complications of ERCP. Gastrointest Endosc 2012; 75: 467-73.

35. Li GZ, Wang F, Fang J, Zha H, Zhao Q. Risk factors for post-endoscopic retrograde cholangiopancreatography pancreatitis: evidence from 1786 cases. Med Sci Monit 2018; 24: 8544-52.

36. Silviera ML, Seamon MJ, Porshinsky B, Prosciak MP, Doraiswamy VA, Wang $C F$, et al. Complications related to endoscopic retrograde cholangiopancreatography: a comprehensive clinical review. J Gastrointestin Liver Dis 2009; 18: 73-82.

37. Minaga K, Kitano M, Imai H, Yamao K, Kamata K, Miyata $T$, et al. Urgent endoscopic ultrasound-guided choledochoduodenostomy for acute obstructive suppurative cholangitis-induced sepsis. World J Gastroenterol 2016; 22: 4264-9. 